BMJ Open

Diabetes

Research

\& Care

\title{
Carbohydrate-last meal pattern lowers postprandial glucose and insulin excursions in type 2 diabetes
}

\author{
Alpana P Shukla, ${ }^{1}$ Jeselin Andono, ${ }^{1,2}$ Samir H Touhamy, ${ }^{1,2}$ Anthony Casper, ${ }^{1}$ \\ Radu G Iliescu, ${ }^{1}$ Elizabeth Mauer, ${ }^{3}$ Yuan Shan Zhu, ${ }^{4}$ David S Ludwig, ${ }^{5}$ \\ Louis J Aronne ${ }^{1}$
}

To cite: Shukla AP,

Andono J, Touhamy SH, et al. Carbohydrate-last meal pattern lowers postprandial glucose and insulin excursions in type 2 diabetes. BMJ Open Diab Res Care 2017;5:e000440. doi:10.1136/ bmjdrc-2017-000440

Received 9 May 2017 Revised 8 August 2017 Accepted 14 August 2017

\section{(a) CrossMark}

${ }^{1}$ Comprehensive Weight Control Center, Division of Endocrinology, Diabetes, \& Metabolism, Weill Cornell Medical College, New York, NY, USA

Institute of Human Nutrition, Columbia University, New York, USA

${ }^{3}$ Department of Healthcare Policy and Research, Weill Cornell Medical College, New York, USA

${ }^{4}$ Department of Medicine, Clinical and Translational Science Center, Weill Cornell Medical College, New York, USA ${ }^{5}$ The New Balance Foundation Obesity Prevention Center, Department of Medicine, Boston Children's Hospital, Boston, Massachusetts, USA

\section{Correspondence to} Dr Alpana P Shukla; aps2004@med.cornell.edu

\section{ABSTRACT}

Background There are limited data regarding the timing of carbohydrate ingestion during a meal and postprandial glucose regulation.

Methods Sixteen subjects with type 2 diabetes mellitus (T2DM) consumed the same meal on 3 days in random order: carbohydrate first, followed 10 min later by protein and vegetables; protein and vegetables first, followed 10 min later by carbohydrate; or all components together. Blood was sampled for glucose, insulin, glucagon-like peptide-1 (GLP-1), and glucagon measurements at baseline (just before meal ingestion) and subsequently at $30 \mathrm{~min}$ intervals up to $180 \mathrm{~min}$.

Results The incremental areas under the curve for glucose ( $\left.\mathrm{iAUC}_{0-180}\right)$ and incremental glucose peaks were $53 \%$ and $54 \%$ lower, respectively, when carbohydrate was consumed last compared with carbohydrate consumed first $(3124.7 \pm 501.2$ vs $6703.5 \pm 904.6 \mathrm{mg} /$ $\mathrm{dL} \times 180 \mathrm{~min}, \mathrm{p}<0.001 ; 34.7 \pm 4.1 \mathrm{vs} 75.0 \pm 6.5 \mathrm{mg} /$ $\mathrm{dL}, \mathrm{p}<0.001$ ) and $44 \%$ and $40 \%$ lower, respectively, compared with the all components together condition $(3124.7 \pm 501.2$ vs $5587.1 \pm 828.7 \mathrm{mg} / \mathrm{dL} \times 180 \mathrm{~min}$, $p=0.003 ; 34.7 \pm 4.1$ vs $58.2 \pm 5.9 \mathrm{mg} / \mathrm{dL}, p<0.001)$. Postprandial insulin excursions were lower ( $\mathrm{AAUC}_{0-180}$ : $7354.1 \pm 897.3$ vs $9769.7 \pm 1002.1 \mu \mathrm{U} / \mathrm{mL} \times \mathrm{min}, \mathrm{p}=0.003)$ and GLP-1 excursions higher (iAUC ${ }_{0-180}: 3487.56 \pm 327.7$ vs $2519.11 \pm 494.8 \mathrm{pg} / \mathrm{mL} \times \mathrm{min}, \mathrm{p}=0.019$ ) following the carbohydrate-last meal order compared with carbohydrate first.

Conclusion The carbohydrate-last meal pattern may be an effective behavioral strategy to improve postprandial glycemia.

Postprandial hyperglycemia is an independent risk factor for both macrovascular ${ }^{1}$ and microvascular ${ }^{2}$ complications of type 2 diabetes mellitus (T2DM) and is the major determinant of glucose control at glycated hemoglobin (HbA1c) values below 7.3\%. ${ }^{3}$ Current nutritional strategies to attenuate postprandial glucose excursions are based on the quantity and type of carbohydrate consumed as the primary predictors of glycemic response. Beyond carbohydrate type and amount, postmeal glucose excursions can

\section{Significance of this study}

What is already known about this subject?

- Limited data on nutrient order during a meal suggests that consuming carbohydrate last lowers postprandial glucose excursions compared to carbohydrate consumed first. Protein preload stimulates insulin and incretin hormone secretion resulting in a lower postprandial glucose response.

\section{What are the new findings?}

- The carbohydrate-last meal pattern reduced postprandial glucose excursions compared to consuming carbohydrate first or all meal components together.

- In contrast to protein preloads, the carbohydratelast meal pattern lead to lower glycemic and insulin excursions but higher glucagon-like peptide-1 response.

\section{Current research questions?}

- Generalizability to meals with different macronutrient composition and different subsets of patients, for example, Type 1, prediabetes

- Effect of the sequence of nutrient ingestion on gastric emptying and rates of nutrient absorption

How might these results change the focus of research or clinical practice?

- The carbohydrate-last meal pattern may be an effective behavioral strategy to improve postprandial glucose control in patients with type 2 diabetes mellitus; feasibility and effectiveness need to be assessed in prospective studies.

be attenuated by fat and protein preloads ${ }^{4-7}$ and by a modified macronutrient composition that includes more protein ${ }^{8}$ and dietary fiber. $^{9}$

A study in eight subjects with T2DM demonstrated that whey protein consumed before a carbohydrate meal can stimulate insulin and incretin hormone secretion and slow gastric emptying, leading to marked reduction in postprandial glycemia. ${ }^{6}$ These findings were 
confirmed in a subsequent study of 15 subjects that showed a $28 \%$ reduction in postprandial glucose excursions over $180 \mathrm{~min}$ that was accompanied by an increase in glucagon-like peptide-1 (GLP-1) and insulin responses. ${ }^{7}$ The addition of whey to meals with rapidly digested and absorbed carbohydrates has also been shown to stimulate insulin release and reduce postprandial blood glucose excursion by $21 \%$ after a lunch meal consisting of mashed potatoes and meatballs in subjects with T2DM. ${ }^{4}$

There are limited data, however, regarding the impact of the temporal sequence of carbohydrate ingestion during a meal on postprandial glycemia. ${ }^{10}{ }^{11}$ In a previous pilot study of 11 patients with metformin-treated T2DM, we demonstrated that ingestion of protein and vegetables before carbohydrate led to lower postprandial glucose and insulin excursions for $120 \mathrm{~min}$, compared with eating the same foods in the reverse order. ${ }^{11}$ No study has investigated the effects of the timing of carbohydrate ingestion during a meal on postprandial glucose, insulin and incretin hormone excursions.

The aim of this study was to determine the optimal timing of carbohydrate ingestion during a meal that can lower postprandial glycemia in the setting of three realworld meal conditions and additionally explore the effect of food order on insulin and incretin hormone excursions. We postulated that consuming vegetables and protein together as the first course instead of carbohydrate would result in lower post-meal glucose excursions compared with the reverse order and consuming all meal components (protein, vegetables and carbohydrate) all together would result in intermediate effects.

\section{RESEARCH DESIGN AND METHODS}

\section{Subject inclusion and exclusion criteria}

Male and female participants between 35 and 65 years of age, body mass index (BMI) $25-40 \mathrm{~kg} / \mathrm{m}^{2}$ and metformin-treated T2DM of less than 10 years duration with $\mathrm{HbAlc} \leq 8 \%$ were included in the study.

Patients taking corticosteroids, antidiabetic medication other than metformin, and patients with chronic renal or hepatic disease or history of prior bariatric surgery were excluded. The study was approved by the Weill Cornell Medical College Institutional Review Board (IRB\#1502015945). All participants gave written informed consent.

\section{Study protocol}

We used a crossover design in which all participants consumed isocaloric meals (table 1 ) of the same composition on three separate days, 1 week apart, after a 12 hours overnight fast. Participants were instructed to maintain their usual level of physical activity and diet throughout the study period and in particular the day prior to each test session. All meals were prepared in the metabolic kitchen of the Clinical and Translational Science Center at Weill Cornell Medical College. Each

\begin{tabular}{|c|c|c|c|}
\hline \multicolumn{2}{|c|}{ Orange juice (no pulp) } & $120 \mathrm{~g}$ & \\
\hline \multicolumn{2}{|c|}{ Ciabatta bread } & $90 \mathrm{~g}$ & \\
\hline \multicolumn{2}{|c|}{ Butter (unsalted) } & $5 \mathrm{~g}$ & \\
\hline \multicolumn{2}{|c|}{$\begin{array}{l}\text { Chicken breast (skinless, } \\
\text { flame grilled) }\end{array}$} & $150 \mathrm{~g}$ & \\
\hline \multicolumn{2}{|c|}{ Lettuce (Romaine) } & $45 \mathrm{~g}$ & \\
\hline \multicolumn{2}{|l|}{ Tomatoes } & $50 \mathrm{~g}$ & \\
\hline \multicolumn{2}{|c|}{ Cucumber (with skin) } & $75 \mathrm{~g}$ & \\
\hline \multicolumn{2}{|c|}{ Salad dressing (Italian, fat free) } & $15 \mathrm{~g}$ & \\
\hline Calories (kJ) & Protein (g) & Fat $(g)$ & Carbohydrate (g) \\
\hline 2403.42 & 55.30 & 9.62 & 64.47 \\
\hline
\end{tabular}

meal was consumed in $30 \mathrm{~min}$, under the following conditions that were randomly assigned using research randomizer:

1. Carbohydrate first $(\mathrm{CF})$ (ciabatta bread and orange juice) over $10 \mathrm{~min}$, a $10 \mathrm{~min}$ rest interval, and then protein (skinless grilled chicken breast) and vegetables (lettuce, tomatoes and cucumber with Italian vinaigrette) over $10 \mathrm{~min}$.

2. Protein and vegetables first over $10 \mathrm{~min}$, a $10 \mathrm{~min}$ rest interval, and then carbohydrate over $10 \mathrm{~min}$ (carbohydrate last (CL)).

3. All meal components together as a sandwich with each half consumed with half the orange juice over $10 \mathrm{~min}$ and a $10 \mathrm{~min}$ interval in between (sandwich (S)).

Participants were closely monitored to ensure that all meals were consumed in their entirety within the allotted time. Blood samples were drawn from an in-dwelling venous cannula at baseline (just before meal ingestion) and at $30 \mathrm{~min}$ intervals up to $180 \mathrm{~min}$ after the start of the meal. Glucose concentrations were assessed in whole blood using a quantitative enzymatic photometry cassette from Alere (San Diego, California, USA). The intra-assay and inter-assay coefficients of variation are $\leq 6.2 \%$ and $\leq 5.0 \%$, respectively. The plasma concentrations of insulin and glucagon were determined using quantitative immunoradiometric assay kits from Millipore (St. Charles, Missouri, USA). The intra-assay and inter-assay coefficients of variation are $\leq 4.4 \%$ and $\leq 6.0 \%$ for insulin and $\leq 4.8 \%$ and $\leq 6.4 \%$ for glucagon, respectively. The measurement range is $3.125-200.0 \mu \mathrm{U} / \mathrm{mL}$ for insulin and $4.7-150 \mathrm{pmol} / \mathrm{L}$ for glucagon. The plasma concentration of active GLP-1 was determined using an electrochemiluminescent assay kit from Meso Scale Diagnostics (Rockville, Maryland, USA) with collection of blood samples in the BD P800 blood collection tube containing a proprietary cocktail of protease, esterase and dipeptidyl peptidase IV inhibitors which provides immediate protection of bioactive peptides from degradation in plasma. The intra-assay and inter-assay coefficients of variation are $\leq 11.2 \%$ and $\leq 13.4 \%$, respectively, and the measurement range is $0.24-1000 \mathrm{pg} / \mathrm{mL}$. 


\section{Statistical analysis}

Demographics for participants were described as mean \pm SD. Glucose, insulin, iGLP-1 and glucagon concentrations (at time intervals of interest) and their respective incremental areas under the curves (iAUCs) at $180 \mathrm{~min}$ were described as mean \pm SEM for each group. Incremental glucose peaks were also described as mean \pm SEM. Linear mixed effects models accounting for correlation within the same participant were implemented for each outcome of interest to compare the three groups. Post-hoc analyses were performed by Tukey's method with Bonferroni adjustment. $p$ Values were two-sided with statistical significance evaluated at the 0.05 alpha level or the Bonferroni-corrected 0.05 alpha level, where applicable. Analyses were performed in R V.3.4.0 (Vienna, Austria).

\section{RESULTS}

The study population included 16 participants with overweight/obesity (nine female and seven male) with T2DM on a stable dose of metformin. The average $($ mean \pm SD) age and BMI were $57.7 \pm 7.6$ years and $32.8 \pm 3.3 \mathrm{~kg} / \mathrm{m}^{2}$, respectively. The average duration of diabetes among the participants was $3.8 \pm 2.4$ years and the mean $\mathrm{HbAlc}$ was $6.5 \% \pm 0.7 \%$. One participant did not have sandwich data; however, this participant was not lost in analyses because mixed effects models handle missing values by maximum likelihood estimation and are robust to missing random data. However, sensitivity analyses by excluding this participant did not change the significance of results.

There were no differences between baseline fasting glucose concentrations in the three meal conditions. Postprandial mean glucose concentrations were significantly decreased by $20.8 \%, 30.2 \%$, and $23.1 \%$ at 30,60 , and $90 \mathrm{~min}$ (figure 1), respectively, and the $\mathrm{iAUC}_{0-180}$ was $53.4 \%$ lower $(3124.7 \pm 501.2$ vs $6703.5 \pm 904.6 \mathrm{mg}$ / $\mathrm{dL} \times 180 \mathrm{~min}, \mathrm{p}<0.001)$ following the $\mathrm{CL}$ meal order, compared with $\mathrm{CF}$, the reverse meal order (table 2). CL meal pattern showed reduced postprandial glucose levels compared with the $\mathrm{S}$ meal pattern: a decrease of $19.8 \%, 25.2 \%$, and $15.3 \%$ at 30,60 , and $90 \mathrm{~min}$, respectively, and a decrease in iAUC $_{0-180}$ of $44.1 \%$ (3124.7 \pm 501.2 vs $5587.1 \pm 828.7 \mathrm{mg} / \mathrm{dL} \times 180 \mathrm{~min}, \mathrm{p}=0.003)$. Following the CL meal order, glucose levels plateaued between 90 and $180 \mathrm{~min}$ postprandially, whereas, there were marked fluctuations in glucose concentrations in the CF meal condition, with the glucose level being significantly lower than CL at $180 \mathrm{~min}$. Incremental glucose peaks were $53.8 \%$ and $40.4 \%$ lower for the CL meal order compared with $\mathrm{CF}$ and S, respectively $(34.7 \pm 4.1$ vs $75.0 \pm 6.5 \mathrm{mg} / \mathrm{dL}, \mathrm{p}<0.001 ; 34.7 \pm 4.1$ vs $58.2 \pm 5.9 \mathrm{mg} /$ $\mathrm{dL}, \mathrm{p}<0.001)$ and $22.4 \%$ lower for $\mathrm{S}$ compared with CF $(58.2 \pm 5.9 \mathrm{mg} / \mathrm{dL}$ vs $75.0 \pm 6.5 \mathrm{mg} / \mathrm{dL}, \mathrm{p}<0.001)$.

The CL meal resulted in lower insulin excursions; iAUC $_{0-180}$ was $24.8 \%$ lower compared with $\mathrm{CF}$ $(7354.1 \pm 897.3$ vs $9769.7 \pm 1002.1 \mu \mathrm{U} / \mathrm{mL} \times 180 \mathrm{~min}$,
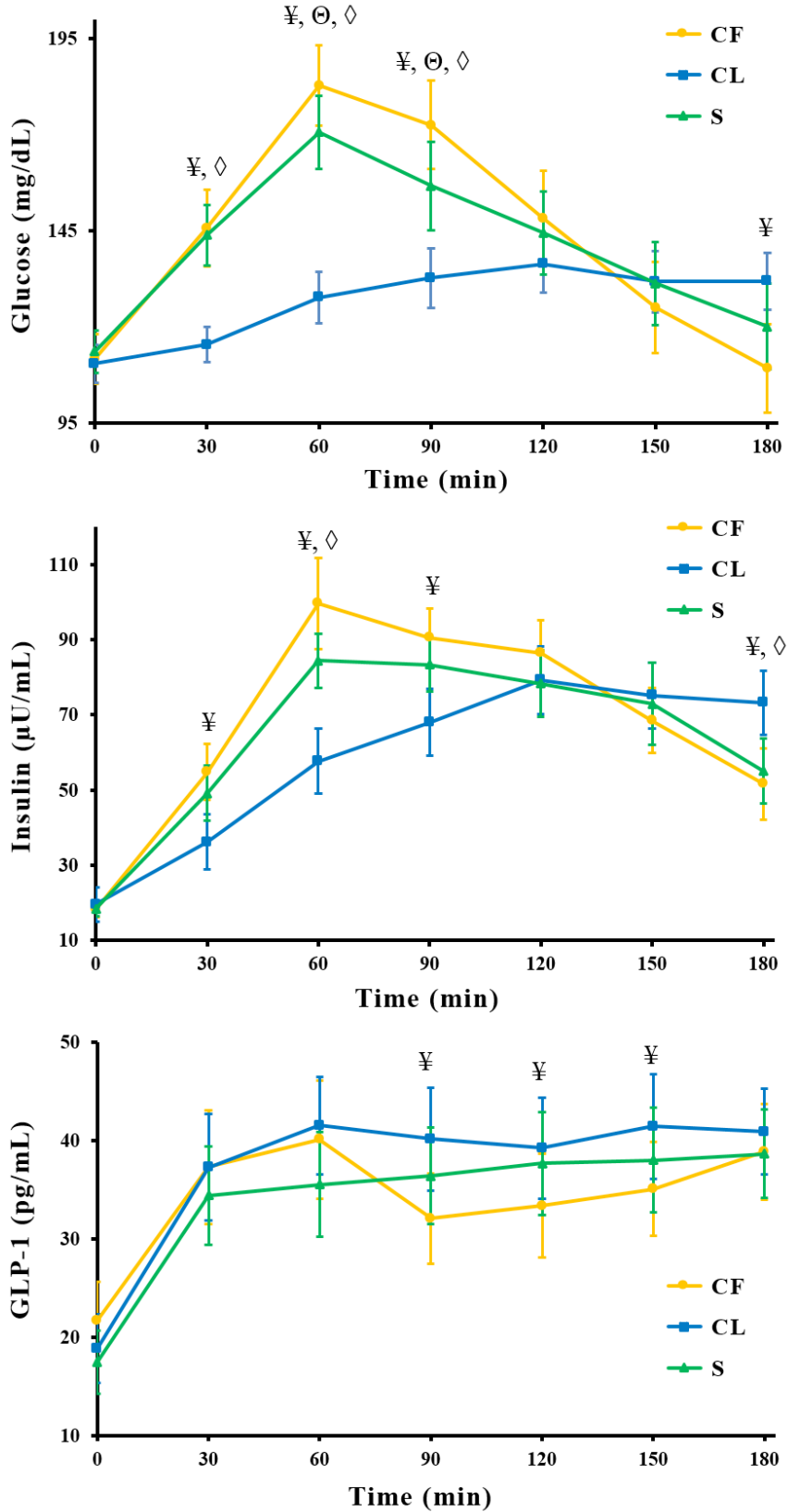

Figure 1 Postprandial glucose, insulin and glucagonlike peptide-1 (GLP-1) levels following carbohydrate-first $(\mathrm{CF})$, carbohydrate-last (CL) and sandwich (S) meal orders. Values are mean \pm SEM. $¥$ Statistically significant differences $(p<0.05)$ between CF and CL. $\Theta$ Statistically significant differences $(p<0.05)$ between CF and $S$. $\diamond$ Statistically significant differences $(p<0.05)$ between $C L$ and $S$.

$p=0.003$ ). The insulin excursions were not significantly different between the $\mathrm{CF}$ and $\mathrm{S}$ meal conditions $(7354.1 \pm 897.3$ vs $8861.2 \pm 1050.5 \mu \mathrm{U} / \mathrm{mL} \times 180 \mathrm{~min}$, $\mathrm{p}=0.137$ ). The GLP-1 response to the CL meal order was greater compared with CF $(3487.56 \pm 327.7$ vs $2519.11 \pm 494.8 \mathrm{pg} / \mathrm{mL} \times 180 \mathrm{~min}, \quad \mathrm{p}=0.019)$ and similar to the $\mathrm{S}$ meal condition $(3487.56 \pm 327.7$ vs $3153.2 \pm 449.4 \mathrm{pg} / \mathrm{mL} \times 180 \mathrm{~min}, \mathrm{p}=0.999)$. The glucagon excursions were not significantly different between the three meal conditions. 
Table 2 Incremental areas under the curves (iAUCs) (0-180 min) during the three visits

Time (min)†‡ Carbohydrates first (CF) Carbohydrates last (CL) Sandwich (S)

\begin{tabular}{|c|c|c|c|c|}
\hline $\begin{array}{l}\text { Glucose iAUC } \\
\text { (mmol/L×min)* }^{*}\end{array}$ & $0-180$ & $372.0 \pm 50.2 \S$ & $173.4 \pm 27.8 \S 9$ & $310.08 \pm 46.0$ १ \\
\hline $\begin{array}{l}\text { Insulin iAUC } \\
(\mathrm{pmol} / \mathrm{L} \times \mathrm{min})^{\star}\end{array}$ & $0-180$ & $67850.6 \pm 6959.6 \S$ & $51074.2 \pm 6231.7 \S$ & $61541.0 \pm 7295.7$ \\
\hline $\begin{array}{l}\text { Glucagon-like peptide-1 iAUC } \\
(\text { (pmol/L×min) })^{*}\end{array}$ & $0-180$ & $763.8 \pm 150.0 \S$ & $1057.4 \pm 99.4 \S$ & $956.1 \pm 136.3$ \\
\hline
\end{tabular}

*Values are expressed in SI units as mean \pm SEM, $\mathrm{n}=16$.

†Blood samples were collected immediately before the meal $(\mathrm{t}=0 \mathrm{~min})$ and at $30,60,90$, and $180 \mathrm{~min}$ after the start of the meal.

†Intervals were measured in minutes from the start of the meal. The 30-minute time point was immediately collected after the meal was finished.

§Statistically significant differences $(p<0.05)$ between CF and CL.

IStatistically significant differences $(p<0.05)$ between $C L$ and $S$.

\section{CONCLUSIONS}

In this study, we demonstrated that the temporal sequence of carbohydrate ingestion during a meal has significant impact on postprandial glucose regulation. These findings confirm and extend results from our previous pilot study ${ }^{11}$; the inclusion of a third nutrient order condition, a sandwich, had intermediate effects on glucose excursions compared with $\mathrm{CL}$ versus $\mathrm{CF}$.

Previous studies investigating the effect of premeal ingestion of whey protein have demonstrated that the glucose-lowering effect is accompanied by an insulinotropic response. ${ }^{67}$ In contrast, our results demonstrate that consumption of protein and vegetables first, followed by carbohydrate, reduces both postmeal glucose and insulin excursions, suggesting that the CL meal pattern requires less insulin controlling for carbohydrate amount.

Modifying the rate of nutrient absorption is a therapeutic principle of particular relevance to diabetes. A plausible explanation for the attenuated glycemic response observed with the CL meal pattern is delayed gastric emptying and consequently slower rates of carbohydrate absorption, a mechanism that would not be entirely mediated by GLP-1. The finding of lower insulin iAUC in the context of increased GLP-1 excursions contrasts with the effect of protein preloads that augment both GLP-1 and insulin secretion ${ }^{6712}$ and suggests a role for vegetable fiber in moderating this response.

The effect of food order on postprandial glycemia in this study is comparable to the magnitude observed with pharmacological agents that preferentially target postprandial glycemia; acarbose and nateglinide reduce iAUCs by $31 \%$ and $64 \%$, respectively, compared with placebo. ${ }^{13}{ }^{14}$ In non-insulin treated patients, managed with diet/oral hypoglycemic agents, pramlintide was shown to lower glucose excursions by $57 \% .{ }^{15}$ Limitations of our study include the small sample size and unclear generalizability to meals with different macronutrient compositions and patient populations including those with type 1 diabetes and prediabetes. Further study is needed to explore the mechanisms, including gastric emptying and rates of nutrient absorption with extended follow-up beyond $180 \mathrm{~min}$. Strengths of the study include stringent study design and the use of real-world meals that suggest practical utility. In conclusion, our findings suggest that the timing of carbohydrate intake during a meal may have major effects on postprandial glucose excursions comparable in magnitude to many hypoglycemic drugs.

Acknowledgements APS and LJA are the guarantors of this work and, as such, had full access to all the data in the study and take responsibility for the data and the accuracy of the data analysis.

Contributors APS, DSL and LJA: study concept and design. APS: drafting of the manuscript. APS, JA, SHT, AC and YSZ: conduct of study procedures and data acquisition. RGI and EM: data analysis. APS, JA, SHT and LJA: data interpretation. All the authors contributed to the reviewing and editing of the manuscript. APS and LJA are the guarantors of this work and, as such, had full access to all the data in the study and take responsibility for the data and the accuracy of the data analysis.

Funding Louis \& Rachel Rudin Foundation Grant, Diane \& Darryl Mallah.

Disclaimer LJA and DSL report receiving royalties for books on nutrition and obesity.

Competing interests None declared.

Patient consent Obtained.

Ethics approval Weill Cornell Medical College Institutional Review Board. Provenance and peer review Not commissioned; externally peer reviewed.

Open Access This is an Open Access article distributed in accordance with the Creative Commons Attribution Non Commercial (CC BY-NC 4.0) license, which permits others to distribute, remix, adapt, build upon this work non-commercially, and license their derivative works on different terms, provided the original work is properly cited and the use is non-commercial. See: http://creativecommons.org/ licenses/by-nc/4.0/

C Article author(s) (or their employer(s) unless otherwise stated in the text of the article) 2017. All rights reserved. No commercial use is permitted unless otherwise expressly granted.

\section{REFERENCES}

1. Cavalot F, Petrelli A, Traversa M, et al. Postprandial blood glucose is a stronger predictor of cardiovascular events than fasting blood glucose in type 2 diabetes mellitus, particularly in women: lessons from the San Luigi Gonzaga Diabetes Study. J Clin Endocrinol Metab 2006;91:813-9.

2. Leiter LA, Ceriello A, Davidson JA, et al. Postprandial glucose regulation: new data and new implications. Clin Ther 2005.

3. Monnier L, Lapinski $\mathrm{H}$, Colette $\mathrm{C}$. Contributions of fasting and postprandial plasma glucose increments to the overall diurnal 
hyperglycemia of type 2 diabetic patients: variations with increasing levels of $\mathrm{HbA}(1 \mathrm{c})$. Diabetes Care 2003;26:881-5.

4. Frid $\mathrm{AH}$, Nilsson M, Holst JJ, et al. Effect of whey on blood glucose and insulin responses to composite breakfast and lunch meals in type 2 diabetic subjects. Am J Clin Nutr 2005;82:69.

5. Gentilcore D, Chaikomin R, Jones KL, et al. Effects of fat on gastric emptying of and the glycemic, insulin, and incretin responses to a carbohydrate meal in type 2 diabetes. $J$ Clin Endocrinol Metab 2006;91:2062-7.

6. Ma J, Stevens JE, Cukier K, et al. Effects of a protein preload on gastric emptying, glycemia, and gut hormones after a carbohydrate meal in diet-controlled type 2 diabetes. Diabetes Care 2009;32:1600-2.

7. Jakubowicz D, Froy $\mathrm{O}$, Ahrén $\mathrm{B}$, et al. Incretin, insulinotropic and glucose-lowering effects of whey protein pre-load in type 2 diabetes: a randomised clinical trial. Diabetologia 2014;57:1807-11.

8. Nuttall FQ, Gannon MC. Metabolic response of people with type 2 diabetes to a high protein diet. Nutr Metab 2004;1:6.

9. Chandalia M, Garg A, Lutjohann D, et al. Beneficial effects of high dietary fiber intake in patients with type 2 diabetes mellitus. $N$ Engl $J$ Med 2000;342:1392-8.
10. Imai S, Fukui M, Kajiyama S. Effect of eating vegetables before carbohydrates on glucose excursions in patients with type 2 diabetes. J Clin Biochem Nutr 2014;54:7-11.

11. Shukla AP, lliescu RG, Thomas CE, et al. Food order Has a significant impact on postprandial glucose and insulin levels. Diabetes Care 2015;38:e98-e99.

12. Marathe CS, Rayner CK, Jones KL, et al. Relationships between gastric emptying, postprandial glycemia, and incretin hormones. Diabetes Care 2013;36:1396-405.

13. Shimabukuro M, Higa N, Chinen I, et al. Effects of a single administration of acarbose on postprandial glucose excursion and endothelial dysfunction in type 2 diabetic patients: a randomized crossover study. J Clin Endocrinol Metab 2006;91:837-42.

14. Gribble FM, Manley SE, Levy JC. Randomized dose ranging study of the reduction of fasting and postprandial glucose in type 2 diabetes by nateglinide (A-4166). Diabetes Care 2001;24:1221-5.

15. Thompson RG, Gottlieb A, Organ K, et al. Pramlintide: a human amylin analogue reduced postprandial plasma glucose, insulin, and C-peptide concentrations in patients with type 2 diabetes. Diabet Med 1997;14:547-55 